\title{
Dopamine Modulates Risk-Taking as a Function of Baseline Sensation-Seeking Trait
}

\author{
Agnes Norbury, ${ }^{1,2}$ Sanjay Manohar, ${ }^{1,2}$ Robert D. Rogers, ${ }^{3}$ and Masud Husain ${ }^{1,2,4}$ \\ ${ }^{1}$ Institute of Cognitive Neuroscience, University College London, London WC1N 3AR, United Kingdom, ${ }^{2}$ Institute of Neurology, University College London, \\ London WC1N 3BG, United Kingdom, ${ }^{3}$ Department of Psychiatry, University of Oxford, Warneford Hospital, Oxford OX3 7JX, United Kingdom, and \\ ${ }^{4}$ Department of Experimental Psychology and Nuffield Department of Clinical Neurosciences, University of Oxford, Oxford OX1 3UD, United Kingdom
}

Trait sensation-seeking, defined as a need for varied, complex, and intense sensations, represents a relatively underexplored hedonic drive in human behavioral neuroscience research. It is related to increased risk for a range of behaviors including substance use, gambling, and risky sexual practice. Individual differences in self-reported sensation-seeking have been linked to brain dopamine function, particularly at D2-like receptors, but so far no causal evidence exists for a role of dopamine in sensation-seeking behavior in humans. Here, we investigated the effects of the selective D2/D3 agonist cabergoline on performance of a probabilistic risky choice task in healthy humans using a sensitive within-subject, placebo-controlled design. Cabergoline significantly influenced the way participants combined different explicit signals regarding probability and loss when choosing between response options associated with uncertain outcomes. Importantly, these effects were strongly dependent on baseline sensation-seeking score. Overall, cabergoline increased sensitivity of choice to information about probability of winning; while decreasing discrimination according to magnitude of potential losses associated with different options. The largest effects of the drug were observed in participants with lower sensation-seeking scores. These findings provide evidence that risk-taking behavior in humans can be directly manipulated by a dopaminergic drug, but that the effectiveness of such a manipulation depends on baseline differences in sensation-seeking trait. This emphasizes the importance of considering individual differences when investigating manipulation of risky decision-making, and may have relevance for the development of pharmacotherapies for disorders involving excessive risk-taking in humans, such as pathological gambling.

\section{Introduction}

Interesting gaps exist between normative accounts of decisionmaking and everyday human behavior (Kahneman and Tversky, 1984). For example, what motivates people to go sky-diving, eat spicy food, or queue for hours for a rollercoaster ride that lasts minutes? A key concept in the study of personality has been the existence of a trait concerned with hedonic drive to seek out intense "sensations," and to tolerate the possibility of aversive outcomes (risk) for the sake of such sensory experiences (Zuckerman, 1974).

Support for the idea of a single trait relating to motivation for intensity of experience across sensory modalities is derived from the observation of covariance of cigarette, alcohol, and caffeine consumption; drug use; and risky sexual behavior in both adults and adolescents (Carmody et al., 1985; Gillespie et al., 2012; King et al., 2012). Evidence for a concomitant alteration in risk tolerance is provided by an association between high self-reported

\footnotetext{
Received Dec. 4, 2012; revised April 15, 2013; accepted April 19, 2013.

Author contributions: A.N., S.M., and M.H. designed research; A.N. and S.M. performed research; A.N. analyzed data; A.N., R.D.R., and M.H. wrote the paper.

This work was supported by the Wellcome Trust and the United Kingdom Medical Research Council.

The authors declare no competing financial interests.

This article is freely available online through the J Neurosci Author Open Choice option.

Correspondence should be addressed to Agnes Norbury, Institute of Cognitive Neuroscience, University College

London, London WC1N 3AR, UK. E-mail: agnes.norbury.10@ucl.ac.uk

DOI:10.1523/JNEUROSCI.5587-12.2013

Copyright $\odot 2013$ the authors $\quad 0270-6474 / 13 / 3312982-05 \$ 15.00 / 0$
}

sensation-seeking (SS) and increased rates of potentially harmful substance consumption, excessive gambling, and other maladaptive behaviors (Coventry and Brown, 1993; Roberti, 2004; Ersche et al., 2010).

Individual differences in sensation-seeking have been linked to brain dopamine (DA) function, particularly at D2-like (D2/ D3/D4) receptors. In humans, trait SS is associated with genetic variation at D2 and D4 receptor loci (Ratsma et al., 2001; Hamidovic et al., 2009; Derringer et al., 2010), and striatal D2/3 receptor "availability," as estimated via ${ }^{11} \mathrm{C}$-raclopride PET (Gjedde et al., 2010). In rodents, robust operant responding for unconditioned sensory rewards has been shown to be sensitive to both the antipsychotic flupenthixol (a D1-D5 receptor antagonist) and amphetamine (Olsen and Winder, 2009; Shin et al., 2010). However, there is currently no causal evidence in humans for a role of DA in modulating behavior as a function of SS trait.

In this study, we used cabergoline-a drug that has both greater affinity and greater relative specificity for D2-like receptors than agents used in former studies (Kvernmo et al., 2006) - to extend previously inconclusive results on the pharmacological manipulation of risk-taking behavior by D2 agonists (Hamidovic et al., 2008; Riba et al., 2008). Importantly, we also took into account the possibility of variation in drug effects with self-reported SS trait.

Based on functional imaging evidence from patient populations undergoing chronic dopamine agonist treatment (Abler et al., 2009), we predicted that cabergoline would increase the 
influence of information about the likelihood of rewards, while possibly also diminishing the effect of potential negative consequences, during risky or uncertain choice. Although previous studies have reported greater responses to DAergic stimulant drugs in high SS (HSS) volunteers, it has also been suggested that lower sensation-seekers might have a relatively higher gain striatal DA system (Gjedde et al., 2010; see also Discussion), which would predict a greater response to specific agonists in low SS (LSS) subjects. We found that cabergoline significantly influenced choice sensitivity to information about probability and potential loss, and that, critically, the magnitude of these effects was strongly dependent on baseline differences in self-reported SS.

\section{Materials and Methods}

Participants. Participants were 20 healthy males (mean age, 26.7 years; $\mathrm{SD}, 5.67$ years). Exclusion criteria consisted of any current major illness, current or historic incident of psychiatric illness, and/or recreational drug use on more than one occasion during the past 6 months. All subjects gave informed written consent and the study was approved by the University College London ethics committee.

Design. The study was carried out according to a within-subjects double-blind placebo-controlled design. On the first session, participants were screened for drug contraindications, gave informed consent, and were familiarized with the risky decision-making paradigm. Subjects also completed Barratt Impulsivity Scale (BIS-11) and UPPS (urgency; (lack of) premeditation; (lack of) perseverance; sensation-seeking) selfreport measures (Patton et al., 1995; Whiteside and Lynam, 2001), a measure of working memory capacity (forward digit span according to the Wechsler Adult Intelligence Scale-III; The Psychological Corporation, 1997), and a standardized nonverbal measure of mental ability (Raven's 12-item Advanced Progressive Matrices; Pearson Education, 2010). On the second and third (test) sessions, participants arrived in the morning and were administered a tablet containing $20 \mathrm{mg}$ of domperidone (an antiemetic), followed 20 minutes later by either $1.5 \mathrm{mg}$ of cabergoline or a placebo (drug and placebo tablets were indistinguishable). This dose was chosen to be greater than that given in a previous study where inconsistent effects on behavior were observed $(1.25 \mathrm{mg}$; Frank and O'Reilly, 2006), with the addition of domperidone masking to mitigate against potential physical side effects.

To allow drug plasma levels to reach maximum concentration, testing commenced $2 \mathrm{~h}$ after ingestion of the second tablet (Andreotti et al., 1995). On each test session, participants completed visual analog scale measures of mood, affect, physical side effects, and knowledge of the drug/placebo manipulation. Drug/placebo order was counterbalanced across subjects, with a minimum washout period of 2 weeks between the two test sessions.

Risky decision-making paradigm. Risky decision-making was probed using the probabilistic choice task described previously by Rogers and colleagues (Rogers et al., 2003; Murphy et al., 2008). Briefly, on each trial, subjects were required to choose between two simultaneously presented gambles. Each gamble was represented visually by a histogram, the height of which indicated the relative probability of winning a given number of points. The magnitude of possible gains was indicated in green above each histogram, with the magnitude of possible losses indicated underneath in red.

On each trial, one gamble always consisted of a 50:50 chance of winning or losing 10 points (the "control" gamble, expected value 0 ). The alternative ("experimental") gamble varied in (1) probability of winning (0.6 or 0.4$)$, (2) magnitude of possible gains (30 or 70 points), and (3) magnitude of possible losses ( 30 or 70 points).

These gamble properties were completely crossed, yielding eight trial types. Visual feedback (win/lose) was given after each choice was made, and the revised running total of points was presented before the next trial.

Subjects completed four blocks of 20 trials, and were instructed that the highest total score they managed to achieve would be converted into

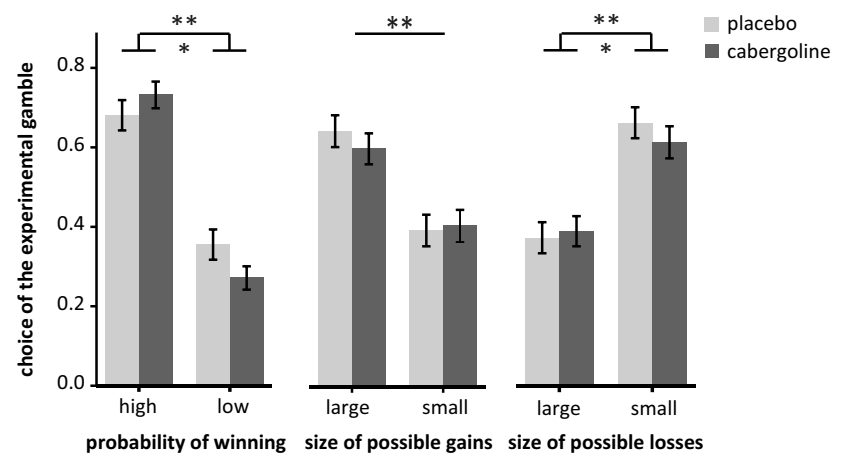

Figure 1. Proportionate choice of the "experimental" gamble according to gamble properties, under placebo and cabergoline. ${ }^{* *} p<0.001,{ }^{*} p<0.05$.

pence and paid at the end of the task as a cash bonus. Deliberation (response) times were also recorded.

Choice data analysis. Data were analyzed as proportionate choice of the "experimental" gamble as a function of probability of winning, size of possible gains, and size of possible losses. Specifically, proportionate choice data were entered into a repeated-measures ANOVA with withinsubjects factors of drug, probability of winning, size of expected gains, and size of expected losses. Treatment order was included as a betweensubjects factor in the model. A similar analysis was performed for the response time data. Choices were also assessed in terms of expected value and "riskiness" of chosen gambles, with the latter defined as the SD of the possible outcomes of each chosen gamble. All reported simple effects analyses were via pairwise comparisons using the Bonferroni adjustment for multiple comparisons. Data from one subject were corrupted and therefore excluded from the analysis.

\section{Results}

\section{Proportionate choice data}

No significant main effect of drug order, or interaction between factors of drug and drug order, was found (both $p>0.09$ ). To maximize power, drug order was therefore discarded from the model for subsequent analyses. In general, participants chose the "experimental" gamble significantly more often when its probability of winning was high compared with when it was low $\left(F_{(1,18)}=40.305, p<0.001, \eta_{p}{ }^{2}=0.691\right)$. This pattern of decision-making was significantly exaggerated under cabergoline relative to placebo (drug ${ }^{\star}$ probability of winning; $F_{(1,18)}=6.733$, $\left.p=0.018, \eta_{p}^{2}=0.272\right)$.

Subjects also chose the "experimental" gamble significantly more often when expected gains were large than when expected gains were small $\left(F_{(1,18)}=50.522, p<0.001, \eta_{p}{ }^{2}=0.736\right)$. However, there was no strong evidence that this pattern of choice was different under cabergoline (drug* size of possible gains, $\left.F_{(1,18)}=3.615, p=0.074\right)$.

Finally, volunteers chose the "experimental" gamble significantly less often when its expected losses were large than when its expected losses were small $\left(F_{(1,18)}=56.486, p=0.001\right.$, $\left.\eta_{p}{ }^{2}=0.758\right)$. This pattern of decision-making was significantly attenuated under cabergoline (drug* size of possible losses, $\left.F_{(1,18)}=6.773, p=0.018, \eta_{p}{ }^{2}=0.273\right)$. For a summary of these effects see Figure 1.

There was no effect of cabergoline on overall proportion of choices of the "experimental" gamble $(p=0.480)$, and no significant higher-order interactions involving the factor of drug (all $p>0.2)$.

\section{Interaction with individual differences}

UPPS SS subscore was found to interact significantly with both effects of drug on choice behavior [drug* probability of winning 

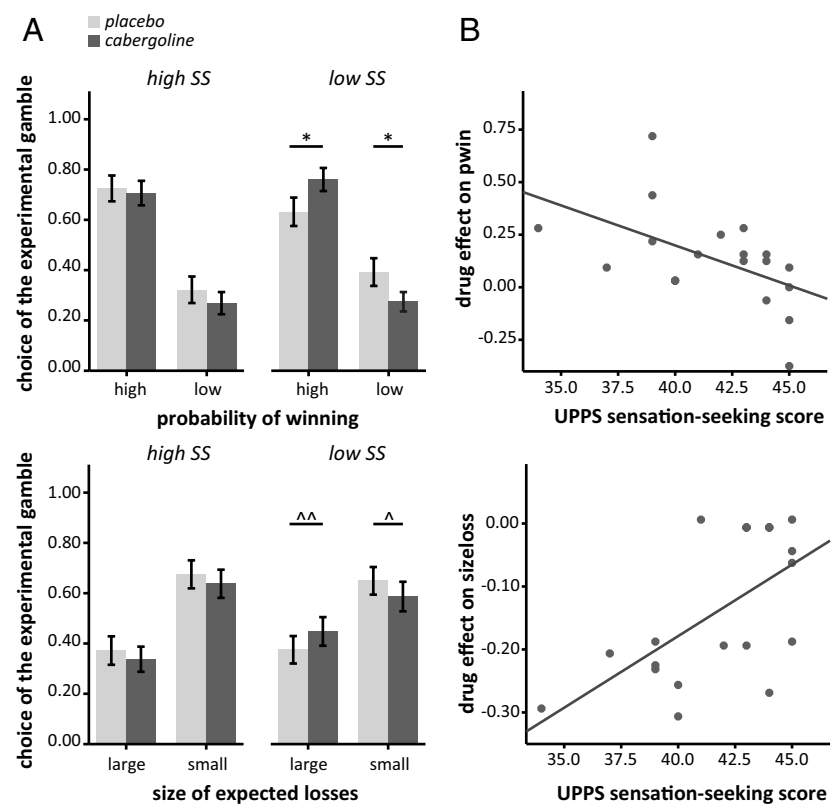

Figure 2. A, Effects of cabergoline on subjects' choice behavior, divided into HSS and LSS groups via a median split of UPPS SS subscale scores. For LSS subjects only, modulation of choice behavior was significantly exaggerated in accordance with information about the probability of winning, and tended to be attenuated in accordance with information about the size of expected losses, on cabergoline relative to placebo (nb SS score was a significant continuous covariate of both effects of drug on choice). ${ }^{*} p<0.05,{ }^{\wedge} p=0.0546,{ }^{\wedge} p<0.10$. $\boldsymbol{B}$, Relationships between magnitude of drug effect indices (difference in magnitude of effect of a change in probability of winning or magnitude of expected loss on proportionate choice of the experimental gamble between drug and placebo conditions) and UPPS SS score ( $r=-0.521$, $p=0.022 ; r=0.611, p=0.005$ ). In both cases, individuals with lower SS scores showed larger effects of cabergoline on their choice behavior.

$(\text { pwin })^{\star}$ SS score, $F_{(1,17)}=6.331, p=0.022, \eta_{p}{ }^{2}=0.271$; drug $^{\star}$ losses $^{\star}$ SS score, $F_{(1,17)}=11.501, p=0.003, \eta_{p}{ }^{2}=0.404$; by comparison, age, estimated IQ, working memory capacity, and total self-reported impulsivity were all $p>0.3$.

Indeed, drug interactions with the factors pwin and size of expected losses appear to be driven mainly by subjects with lower SS scores (Fig. 2A). Simple effects analysis revealed that, when defining LSS and HSS groups by a median split of SS scores, LSSs chose more "experimental" gambles when pwin was high $\left(F_{(1,17)}=5.996, p=0.025\right)$ and fewer when pwin was low $\left(F_{(1,17)}=7.808, p=0.012\right)$ on drug relative to placebo. By contrast, the HSS group did not differ in their choice of low or high pwin options between drug and placebo conditions $(p>0.2)$.

LSSs also showed nonsignificant trends toward choosing fewer gambles when potential losses were small $\left(F_{(1,17)}=4.262\right.$, $p=0.0546)$, and more gambles when potential losses were large $\left(F_{(1,17)}=3.052, p=0.090\right.$; Fig. $\left.2 A\right)$, on cabergoline compared with placebo. Neither of these effects approached significance in the HSS group $(p>0.2)$. HSS and LSS groups did not differ significantly in terms of any other self-reported impulsivity subscale scores, age, digit span, or estimated IQ (all $p>0.3$ ).

To quantify these effects at the individual level, two indices of magnitude of drug effect on choice were calculated for each subject (difference in magnitude of the effect of a change in probability of winning, or magnitude of possible loss, on proportionate choice of the experimental gamble between drug and placebo conditions). SS score was found to be a significant predictor of both these indices $\left(r_{\text {adj }}^{2}=0.229, p=0.022 ; r^{2}\right.$ adj $=0.336, p=$ 0.005 ; linear regression analysis), but not estimated IQ, digit span, or other self-reported impulsivity score (all $p>0.1$ ). In
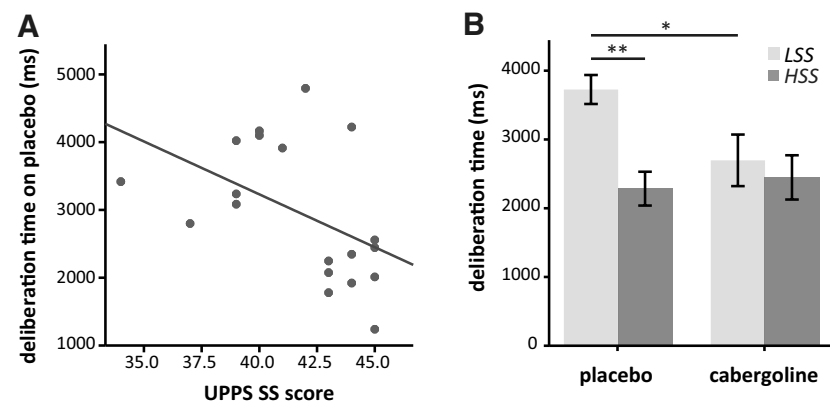

Figure 3. A, Mean choice deliberation time on placebo is negatively correlated with UPPS SS score $(r=-0.479, p=0.038)$. $\boldsymbol{B}$, LSS subjects showed slower choice deliberation times than HSS subjects on placebo sessions only. ${ }^{* *} p<0.001,{ }^{*} p=0.023$.

both cases, participants with lower sensation-seeking scores were more influenced in their behavior by cabergoline (Fig. $2 B)$. The two indices themselves were not significantly related $(p=0.117)$.

\section{Deliberation times}

There were no significant effects of probability of winning, size of possible gains, or size of possible losses on participants' deliberation times (all $F<1$ ), and no significant effect of cabergoline on response timing $(p=0.204)$. There were no significant interaction effects of drug, gamble properties, and SS score on deliberation times (all $p>0.3)$.

\section{Expected value and risk}

Expected value of gambles was significantly linearly related to proportionate choice under both placebo and cabergoline $\left(r_{\text {adj }}^{2}=0.890, p<0.001 ; r^{2}\right.$ adj $=0.737, p=0.004$; regression coefficients not significantly different, $p=0.924)$. Gamble riskiness (SD) was not significantly related to proportionate choice under either drug condition $(p>0.5)$. There was no significant effect of drug on mean expected value $(p=0.582)$ or mean riskiness of chosen gambles $(p=0.376)$. There were also no significant interactions of drug and SS score on these measures $(p>0.2)$.

\section{Individual differences at baseline}

When considering data from the placebo session alone, there were no significant interactions between SS score and the effects of gamble properties (pwin, size of expected gains and losses) on choice (all $p>0.1$ ). There were also no significant relationships between any single choice parameters (i.e., mean chosen gamble riskiness, mean chosen gamble expected value, and total points won) and SS score (all $p>0.1$ ). There was, however, a significant negative correlation between SS score and mean deliberation time on placebo $(r=-0.479, p=0.038$; Fig. $3 A)$, which was not evident under cabergoline $(p>0.5)$. A repeated-measures ANOVA of mean deliberation time with the between-subjects factor of SS group revealed that low SS subjects showed a trend toward significantly slower responding on the placebo session only $\left(\right.$ drug $^{\star}$ SS group interaction, $F_{(1,17)}=4.404, p=0.0511$; Fig. 3B).

\section{Subjective effects}

At an uncorrected threshold, participants were significantly more calm $(p=0.033)$ and drowsy $(p=0.017)$, and also reported slightly more headache $(p=0.020)$, on cabergoline relative to placebo. However, change on any of these measures was not sig- 
nificantly related to either of the drug effect indices, or selfreported SS score (all $p>0.4$ ), suggesting this did not contribute to either the main effects of cabergoline or to individual differences in the effect of cabergoline. No significant effects of drug were found on any other potential physical side effects $(p>$ $0.25)$, mood, or affect scales ( $p>0.16 ; 26$ measures in total) and knowledge of the drug/placebo manipulation was not found to differ significantly between test sessions $\left(t_{1,18}=\right.$ $1.681, p=0.110)$.

\section{Discussion}

In this study, we found significant effects of a single dose of the D2/D3 agonist cabergoline on decision-making under conditions of uncertainty or risk, which, crucially, depended on baseline differences in self-reported SS trait. Overall, the effect of cabergoline was to exaggerate modulation of choice behavior in accordance with explicit signals about the probability of winning, and simultaneously to attenuate modulation of choice in accordance with information about the size of possible losses (Fig. 1). Importantly, the magnitude of the drug effect was significantly moderated by baseline UPPS SS score (Fig. 2) - which accounted for a significant proportion of variance in the magnitude of both effects of cabergoline on risky decision-making ( 23-34\%). In both cases, individuals who reported lower levels of trait SS showed a stronger influence of cabergoline on their choice behavior.

A body of evidence from both human and animal studies implicates variation in D2R-mediated neurotransmission in individual differences in SS behavior (Ratsma et al., 2001; Blanchard et al., 2009; Hamidovic et al., 2009; Gjedde et al., 2010). However, previous attempts to manipulate risky choice directly in both animals and humans using D2ergic drugs have produced inconsistent results (Hamidovic et al., 2008; Riba et al., 2008; St. Onge and Floresco, 2009; Simon et al., 2011). This might in part be attributable to differences in definitions of risk (e.g., variability in potential reward magnitude vs chance of aversive outcome), or due to dose-dependent effects in drug action.

The existence of both presynaptic and postsynaptic D2 receptors means the addition of drug can potentially have opposing effects on dopaminergic transmission (Usiello et al., 2000). While presynaptic D2 autoreceptors negatively regulate phasic DA responses, postsynaptic D2Rs regulate the tonic DA signaling implicated in the representation of risk (Grace, 1991; Fiorillo et al., 2003; Schmitz et al., 2003; Schultz, 2010). This leads to difficulties in interpreting drug effects, particularly at low doses where only higher-affinity inhibitory autoreceptors might be stimulated. We attempted to ensure stimulation of postsynaptic D2Rs by using the high-affinity D2/D3 agonist cabergoline (Kvernmo et al., 2006), at a higher dose than a previous study where inconsistent drug effects were observed (Frank and O'Reilly, 2006). Domperidone masking was used to minimize potentially unblinding side effects, such as nausea, and overall subjects were unaware of the drug/placebo manipulation. We also found no evidence of increased negative affect on the drug, which previously has been taken as an indicator of predominantly presynaptic drug action (e.g., Hamidovic et al., 2008).

Our finding of a greater effect of cabergoline in LSSs might seem somewhat surprising given previous reports that HSSs exhibit increased physiological and subjective responses to dopaminergic stimulants, such as amphetamine (Kelly et al., 2006; Stoops et al., 2007), and that SS score correlates positively with amphetamine-induced DA release in the striatum (Riccardi et al., 2006). However, Gjedde and colleagues have recently argued on the basis of PET evidence that LSSs have both lower D2/D3 receptor density and lower endogenous DA levels than their HSS counterparts, such that the "gain" of the DA system (reactivity to dopamine) in the striatum is inversely related to SS score (Gjedde et al., 2010). Thus LSS participants may have high DA gain. Direct D2 agonists, as used in our study, would therefore be expected to exert greater effects in these individuals.

In support of this hypothesis, there is some evidence that LSSs may have lower endogenous DA levels than HSSs. LSSs exhibit higher platelet levels of monoamine oxidase (a DA catabolist; Zuckerman, 1985; Carrasco et al., 1999), and LSS status has been associated with relatively lower activity dopa decarboxylase (DDC; a rate-limiting enzyme for DA synthesis) in the striatum; via both variation in the DDC gene itself (Derringer et al., 2010) and the Taqla polymorphism (Ratsma et al., 2001; Laakso et al., 2005; Eisenberg et al., 2007). However, there is currently no evidence for increased "gain" (for example, via receptor hypersensitivity) in DA neurotransmission in LSS individuals as a consequence of this.

Our study has some limitations. First, cabergoline is not absolutely specific in its D2R affinity. It also has limited agonist activity at 5- $\mathrm{HT}_{2 \mathrm{~A}}, 5-\mathrm{HT}_{2 \mathrm{~B}}$, and $\mathrm{D} 1$ receptors (Kvernmo et al., 2006). Therefore it is not possible to be completely certain about the mechanism underlying its behavioral effects. Second, although we found no evidence to support an effect of baseline individual differences or increased D2 agonism on choice "riskiness" in terms of variance in potential outcomes, at four levels this comparison was likely underpowered, so this result should not be taken as conclusive. Future experiments using a greater range of gamble risks might investigate this further. In addition, given our sample of 20 subjects, the study might not be optimally powered and its conclusions would benefit from future replication.

Despite its clear clinical relevance, pharmacological manipulation of decision-making under risk is currently relatively underexplored in both humans and animals (Winstanley, 2011). In this study, we provide for the first time to our knowledge evidence baseline differences in SS trait affect the way in which a pharmacological manipulation modifies risk-taking behavior. These findings emphasize the importance of considering individual differences, such as SS, when investigating risky decisionmaking, and may have relevance for the development of pharmacotherapies for disorders involving excessive risk-taking, such as pathological gambling.

\section{References}

Abler B, Hahlbrock R, Unrath A, Grön G, Kassubek J (2009) At-risk for pathological gambling: imaging neural reward processing under chronic dopamine agonists. Brain 132:2396-2402. CrossRef Medline

Andreotti AC, Pianezzola E, Persiani S, Pacciarini MA, Strolin Benedetti M, Pontiroli AE (1995) Pharmacokinetics, pharmacodynamics, and tolerability of cabergoline, a prolactin-lowering drug, after administration of increasing oral doses $(0.5,1.0$, and 1.5 milligrams $)$ in healthy male volunteers. J Clin Endocrinol Metab 80:841-845. CrossRef Medline

Blanchard MM, Mendelsohn D, Stamp JA (2009) The HR/LR model: further evidence as an animal model of sensation seeking. Neurosci Biobehav Rev 33:1145-1154. CrossRef Medline

Carmody TP, Brischetto CS, Matarazzo JD, O’Donnell RP, Connor WE (1985) Co-occurrent use of cigarettes, alcohol, and coffee in healthy, community-living men and women. Health Psychol 4:323-335. CrossRef Medline

Carrasco JL, Sáiz-Ruiz J, Díaz-Marsá, M, César J, López-Ibor JJ (1999) Low platelet monoamine oxidase activity in sensation-seeking bullfighters. CNS Spectr 4:21-24. Medline

Coventry KR, Brown RI (1993) Sensation seeking, gambling and gambling addictions. Addiction 88:541-554. CrossRef Medline 
Derringer J, Krueger RF, Dick DM, Saccone S, Grucza RA, Agrawal A, Lin P, Almasy L, Edenberg HJ, Foroud T, Nurnberger JI Jr, Hesselbrock VM, Kramer JR, Kuperman S, Porjesz B, Schuckit MA, Bierut LJ, Bierut LJ (2010) Predicting sensation seeking from dopamine genes. A candidatesystem approach. Psychol Sci 21:1282-1290. CrossRef Medline

Eisenberg DT, Campbell B, Mackillop J, Lum JK, Wilson DS (2007) Season of birth and dopamine receptor gene associations with impulsivity, sensation seeking and reproductive behaviors. PLoS One 2:e1216. CrossRef Medline

Ersche KD, Turton AJ, Pradhan S, Bullmore ET, Robbins TW (2010) Drug addiction endophenotypes: impulsive versus sensation-seeking personality traits. Biol Psychiatry 68:770-773. CrossRef Medline

Fiorillo CD, Tobler PN, Schultz W (2003) Discrete coding of reward probability and uncertainty by dopamine neurons. Science 299:1898-1902. CrossRef Medline

Frank MJ, O’Reilly RC (2006) A mechanistic account of striatal dopamine function in human cognition: psychopharmacological studies with cabergoline and haloperidol. Behav Neurosci 120:497-517. CrossRef Medline

Gillespie NA, Lubke GH, Gardner CO, Neale MC, Kendler KS (2012) Twopart random effects growth modeling to identify risks associated with alcohol and cannabis initiation, initial average use and changes in drug consumption in a sample of adult, male twins. Drug Alcohol Depend 123:220-228. CrossRef Medline

Gjedde A, Kumakura Y, Cumming P, Linnet J, Møller A (2010) Inverted-Ushaped correlation between dopamine receptor availability in striatum and sensation seeking. Proc Natl Acad Sci U S A 107:3870-3875. CrossRef Medline

Grace AA (1991) Phasic versus tonic dopamine release and the modulation of dopamine system responsivity: A hypothesis for the etiology of schizophrenia. Neuroscience 41:1-24. CrossRef Medline

Hamidovic A, Kang UJ, de Wit H (2008) Effects of low to moderate acute doses of pramipexole on impulsivity and cognition in healthy volunteers. J Clin Psychopharmacol 28:45-51. CrossRef Medline

Hamidovic A, Dlugos A, Skol A, Palmer AA, de Wit H (2009) Evaluation of genetic variability in the dopamine receptor $\mathrm{D} 2$ in relation to behavioral inhibition and impulsivity/sensation seeking: an exploratory study with d-amphetamine in healthy participants. Exp Clin Psychopharmacol 17: 374-383. CrossRef Medline

Kahneman D, Tversky A (1984) Choices, values, and frames. Am Psychol 39:341-350. CrossRef

Kelly TH, Robbins G, Martin CA, Fillmore MT, Lane SD, Harrington NG, Rush CR (2006) Individual differences in drug abuse vulnerability: $\mathrm{d}$-amphetamine and sensation-seeking status. Psychopharmacology (Berl) 189:17-25. CrossRef Medline

King KM, Nguyen HV, Kosterman R, Bailey JA, Hawkins JD (2012) Cooccurrence of sexual risk behaviors and substance use across emerging adulthood: evidence for state- and trait-level associations. Addiction 107: 1288-1296. CrossRef Medline

Kvernmo T, Härtter S, Burger E (2006) A review of the receptor-binding and pharmacokinetic properties of dopamine agonists. Clin Ther 28: 1065-1078. CrossRef Medline

Laakso A, Pohjalainen T, Bergman J, Kajander J, Haaparanta M, Solin O, Syvälahti E, Hietala J (2005) The A1 allele of the human D2 dopamine receptor gene is associated with increased activity of striatal L-amino acid decarboxylase in healthy subjects. Pharmacogenet Genomics 15:387-391. CrossRef Medline

Murphy SE, Longhitano C, Ayres RE, Cowen PJ, Harmer CJ, Rogers RD
(2008) The role of serotonin in nonnormative risky choice: the effects of tryptophan supplements on the "reflection effect" in healthy adult volunteers. J Cogn Neurosci 21:1709-1719. Medline

Olsen CM, Winder DG (2009) Operant sensation seeking engages similar neural substrates to operant drug seeking in C57 mice. Neuropsychopharmacology 34:1685-1694. CrossRef Medline

Patton JH, Stanford MS, Barratt ES (1995) Factor structure of the Barratt Impulsiveness Scale. J Clin Psychol 51:768-774. CrossRef Medline

Ratsma JE, van der Stelt O, Schoffelmeer AN, Westerveld And A, Boudewijn Gunning W (2001) P3 event-related potential, dopamine D2 receptor A1 allele, and sensation-seeking in adult children of alcoholics. Alcoholism 25:960-967. Medline

Riba J, Krämer UM, Heldmann M, Richter S, Münte TF (2008) Dopamine agonist increases risk taking but blunts reward-related brain activity. PLoS One 3:e2479. CrossRef Medline

Riccardi P, Zald D, Li R, Park S, Ansari MS, Dawant B, Anderson S, Woodward N, Schmidt D, Baldwin R, Kessler R (2006) Sex differences in amphetamine-induced displacement of [18F] fallypride in striatal and extrastriatal regions: a PET study. Am J Psychiatry 163:1639-1641. CrossRef Medline

Roberti JW (2004) A review of behavioral and biological correlates of sensation seeking. J Res Pers 38:256-279. CrossRef

Rogers RD, Tunbridge EM, Bhagwagar Z, Drevets WC, Sahakian BJ, Carter CS (2003) Tryptophan depletion alters the decision-making of healthy volunteers through altered processing of reward cues. Neuropsychopharmacology 28:153-162. CrossRef Medline

Schmitz Y, Benoit-Marand M, Gonon F, Sulzer D (2003) Presynaptic regulation of dopaminergic neurotransmission. J Neurochem 87:273-289. CrossRef Medline

Schultz W (2010) Dopamine signals for reward value and risk: basic and recent data. Behav Brain Funct 6:24. CrossRef Medline

Shin R, Cao J, Webb SM, Ikemoto S (2010) Amphetamine administration into the ventral striatum facilitates behavioral interaction with unconditioned visual signals in rats. PLoS One 5:e8741. CrossRef Medline

Simon NW, Montgomery KS, Beas BS, Mitchell MR, LaSarge CL, Mendez IA, Bañuelos C, Vokes CM, Taylor AB, Haberman RP, Bizon JL, Setlow B (2011) Dopaminergic modulation of risky decision-making. J Neurosci 31:17460-17470. CrossRef Medline

St. Onge JR, Floresco SB (2009) Dopaminergic modulation of risk-based decision making. Neuropsychopharmacology 34:681-697. CrossRef Medline

Stoops WW, Lile JA, Robbins CG, Martin CA, Rush CR, Kelly TH (2007) The reinforcing, subject-rated, performance, and cardiovascular effects of $\mathrm{d}$-amphetamine: influence of sensation-seeking status. Addict Behav 32: 1177-1188. CrossRef Medline

Usiello A, Baik JH, Rougé-Pont F, Picetti R, Dierich A, LeMeur M, Piazza PV, Borrelli E (2000) Distinct functions of the two isoforms of dopamine D2 receptors. Nature 408:199-203. CrossRef Medline

Whiteside SP, Lynam DR (2001) The Five Factor Model and impulsivity: using a structural model of personality to understand impulsivity. Pers Indiv Differ 30:669-689. CrossRef

Winstanley CA (2011) The utility of rat models of impulsivity in developing pharmacotherapies for impulse control disorders. Br J Pharmacol 164: 1301-1321. CrossRef Medline

Zuckerman M (1974) The sensation seeking motive. Prog Exp Pers Res 7:79-148. Medline

Zuckerman M (1985) Sensation seeking, mania, and monoamines. Neuropsychobiology 13:121-128. CrossRef Medline 